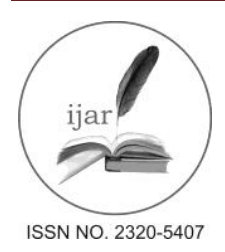

Journal homepage: http://www.journalijar.com
Journal DOI: 10.21474/IJAR01

INTERNATIONAL JOURNAL

OF ADVANCED RESEARCH

RESEARCH ARTICLE

\title{
CLIMATE PREDICTION USING DETERMINISTIC ANN MODEL.
}

\author{
Shailendra Singh ${ }^{1}$, Navita Shrivastava ${ }^{1}$ and Sanjeev Karmakar ${ }^{3}$, R.K. Tiwari ${ }^{4}$. \\ 1. A. P. S. University, Rewa, Madhya Pradesh (India) \\ 2. Bhilai Institute of Technology (BIT), Bhilai House, Durg, CG (India) \\ 3. Govt New Science College, Rewa (M.P.)
}

\section{Manuscript Info}

Manuscript History:

Received: 17 March 2016

Final Accepted: 16 April 2016

Published Online: May 2016

Key words:

BPN Model, LPA, LRF, MSE,

Mean Absolute Deviation, SD etc.

*Corresponding Author

Shailendra Singh.

\begin{abstract}
The ANN based models are most imperative and demanding for climate prediction. Back-Propagation Neural Network is an appropriate methodology in identification of parameters for long-term rainfall data. Presented BPN model is best to identify climatic parameter for prediction as well as forecast rainfall. Forecasting of rainfall over vindhya region has been analyzed through developed BPN model. The observed long period average (LPA) is 956.74 for 45 years data time series of vindhya region. It is observed that the MAD (6.09) is less than the SD (14.37) during the testing period. Correlation coefficient of training period is 0.89 and for testing period is 0.95 . The performance of the model is accurately observed.
\end{abstract}

Copy Right, IJAR, 2016. All rights reserved.

\section{Introduction:-}

IMD's operational model is appropriate for long range forecast of monsoon rainfall over whole central India. However it is unsuccessful in case of long range forecast (LRF) over a very smaller vindhya region which is allocated in central India. The IMD's operational model is based on statistical power regression analysis which uses few global dynamic parameters (i.e., predictors). It is concluded that impact of global parameters (i.e., independent) on the monsoon rainfall (i.e., dependent) over the smaller region is irrelevant. Identification of physically connected global meteorological parameters for monsoon rainfall over smaller region is also extremely difficult. Thus, only alternate solution is deterministic forecast[1]. The ANN techniques are sufficiently suitable in identification of internal dynamics of chaotic time series data. Thus, BPN model in deterministic forecast is used in this study.

The model is operated for LRF of monsoon rainfall over vindhya region for testing period. This study concentrates on the performance of efficiency of BPN model and it is observed that this model is efficient enough for LRF of monsoon rainfall over smaller geographical region like district with higher level of accuracy[2]. The advantage of this study is that, it has been evaluated and concluded that BPN is sufficiently suitable for identification of internal dynamics of high dynamic monsoon rainfall[3]. The model performed well both in training and independent periods [4]. In many other cases BPN is found to be fit for prediction of other climate activities. On the basis of humidity, dew point and pressure in India, Sahai et al and Sawaitul et al $[5,6]$, have used the back propagation neural network model for predicting the rainfall.

In this study, the BPN is used in deterministic forecast for long-range monsoon rainfall for India. The impact of variance in learning rate and momentum factor in the model is also studied.

\section{Data preprocessing:-}

The developed model use time series $\left(X_{i}\right)$ from the year 1970 to 2014 have been constructed for vindhya region. Since, transfer function sigmoid axon is used in the BPN model. The output of sigmoid axon has in close interval 0 to 1 . Therefore, model data time series is normalized and obtained new normalized data time series $\left(R_{i}\right)$. Data time 
series $\left(x_{i}\right)$ for the first 35 years (1970-2004) are used for developing the model. Remaining 10 years (2005-2014) data time series (xi) is used to test the model independently for its acceptance.

Data Normalization and Splitting:-

Data Input:-

Data entry type: Imported from ExcelSheet

Data series name 1: Year $\quad$ Actual and Normalized Data Series: 45 Years

Data series name 2: $\quad$ Rainfall $\quad$ Number of Training Samples : 35 Years

Units $\quad: \quad \mathrm{mm} . \quad$ Number of Testing Samples : 10 Years

Splitting (training and testing dataset) :

Table 1 : Training data set (1970-2004) and Testing dataset (2005-2014)

\begin{tabular}{|c|c|c|c|}
\hline \multicolumn{4}{|c|}{ Training Dataset } \\
\hline Year & $\begin{array}{c}\text { Normalized value of } \\
\text { Rainfall (mm) }\end{array}$ & Year & $\begin{array}{c}\text { Normalized value } \\
\text { of Rainfall (mm) }\end{array}$ \\
\hline 1970 & 0.591377 & 1987 & 0.598493 \\
\hline 1971 & 0.669092 & 1988 & 0.597744 \\
\hline 1972 & 0.631464 & 1989 & 0.537075 \\
\hline 1973 & 0.579184 & 1990 & 0.63936 \\
\hline 1974 & 0.573279 & 1991 & 0.58904 \\
\hline 1975 & 0.632964 & 1992 & 0.532094 \\
\hline 1976 & 0.57478 & 1993 & 0.581387 \\
\hline 1977 & 0.643612 & 1994 & 0.591428 \\
\hline 1978 & 0.651737 & 1995 & 0.622093 \\
\hline 1979 & 0.509426 & 1996 & 0.610391 \\
\hline 1980 & 0.662376 & 1997 & 0.505437 \\
\hline 1981 & 0.600177 & 1998 & 0.564736 \\
\hline 1982 & 0.629964 & 1999 & 0.636996 \\
\hline 1983 & 0.55652 & 2000 & 0.570264 \\
\hline 1984 & 0.605711 & 2001 & 0.639425 \\
\hline 1985 & 0.594553 & 2002 & 0.594851 \\
\hline 1986 & 0.578683 & & \\
\hline \multicolumn{4}{|c|}{$\begin{array}{r}\text { Testing Dataset } \\
\end{array}$} \\
\hline Year & \multicolumn{3}{|c|}{ Normalized value of Rainfall (mm) } \\
\hline 2005 & \multicolumn{3}{|c|}{0.589176} \\
\hline 2006 & \multicolumn{3}{|c|}{0.543197} \\
\hline 2007 & \multicolumn{3}{|c|}{0.539526} \\
\hline 2008 & \multicolumn{3}{|c|}{0.568055} \\
\hline 2009 & \multicolumn{3}{|c|}{0.517473} \\
\hline 2010 & \multicolumn{3}{|c|}{0.551524} \\
\hline 2011 & \multicolumn{3}{|c|}{0.614916} \\
\hline 2012 & \multicolumn{3}{|c|}{0.625406} \\
\hline 2013 & \multicolumn{3}{|c|}{0.64168} \\
\hline 2014 & \multicolumn{3}{|c|}{0.611216} \\
\hline
\end{tabular}


Table 2: Statistics of training dataset and testing dataset

\begin{tabular}{|c|c|c|}
\hline Statistics of Data & Training Dataset & Testing Dataset \\
\hline Min $\left(\mathrm{x}_{\mathrm{i}}\right)$ of Rainfall & 506.6 & 556.6 \\
\hline Max $\left(\mathrm{x}_{\mathrm{i}}\right)$ of Rainfall & 1498.0 & 1268.8 \\
\hline Mean value $\left(\mathrm{x}_{\mathrm{i}}\right)$ & 977.0942857142855 & 885.4799999999999 \\
\hline Standard Deviation $\left(\mathrm{x}_{\mathrm{i}}\right)$ & 244.88219489818215 & 241.67858269472973 \\
\hline \% of Mean $\left(\mathrm{x}_{\mathrm{i}}\right)$ & 25.06228912383474 & 27.293511168488248 \\
\hline & & \\
\hline Minimum normalized value $\left(\mathrm{r}_{\mathrm{i}}\right)$ & 0.5054374937643421 & 0.5174729874428113 \\
\hline Maximum normalized value $\left(\mathrm{r}_{\mathrm{i}}\right)$ & 0.6690921228304405 & 0.6416799190400463 \\
\hline Mean value $\left(\mathrm{r}_{\mathrm{i}}\right)$ & 0.5956103832774173 & 0.5802169069399181 \\
\hline Standard Deviation $\left(\mathrm{r}_{\mathrm{i}}\right)$ & 0.0402430487455586 & 0.04517710183161851 \\
\hline \% of Mean $\left(\mathrm{r}_{\mathrm{i}}\right)$ & 6.756606311010968 & 7.7862436084263615 \\
\hline
\end{tabular}

Initial Variables of BPN:-

Table 3: Initial values of BPN variables.

\begin{tabular}{|c|c|c|c|c|c|}
\hline \multicolumn{2}{|c|}{$\begin{array}{l}\text { A. Weights in hidden layer } \\
V(i, j) ; i=10, j=2\end{array}$} & \multicolumn{2}{|c|}{$\begin{array}{l}\text { B. Biases in hidden layer } \\
\operatorname{Vo}(j) ; j=2\end{array}$} & \multicolumn{2}{|c|}{$\begin{array}{l}\text { B. Weights in output layer } \\
\qquad(\mathrm{j}) ; \mathrm{j}=2\end{array}$} \\
\hline $\mathbf{V}(\mathbf{i}, \mathbf{1})$ & $\mathbf{V}(\mathbf{i}, \mathbf{2})$ & $\operatorname{Vo}(1)$ & Vo(2) & $\mathbf{W}(\mathbf{1})$ & $\mathbf{W}(2)$ \\
\hline 0.88986 & 0.253677 & 0.390054 & 0.694807 & 0.546431 & 0.356959 \\
\hline 0.931142 & 0.094606 & & & & \\
\hline 0.149762 & 0.079962 & & & & \\
\hline 0.83213 & 0.575017 & & & & \\
\hline 0.21428 & 0.651923 & & & & \\
\hline 0.41332 & 0.629334 & & & & \\
\hline 0.44451 & 0.933841 & & & & \\
\hline 0.88121 & 0.437617 & & & & \\
\hline $0.17455 t$ & 0.732116 & & & & \\
\hline 0.435148 & 0.175127 & & & & \\
\hline
\end{tabular}

Selection of parameters (recommended by this model):-

Table 4: BPN parameter setup values.

\begin{tabular}{|l|}
\hline Model recommendation: \\
\hline Momentum factor: 0.2382 \\
\hline $\begin{array}{l}\text { Note : This recommendation is given by desired epochs } 7000000, \text { number of iteration } 5 \text {, number of input } \\
\text { vector }(\mathrm{n}) 10, \text { number of neurons in hidden layer }(\mathrm{p}) 2 .\end{array}$ \\
\hline Number of input vectors $(\mathrm{n}): 10$ \\
\hline Number of neurons in hidden layer $(\mathrm{p}): 2$ \\
\hline Learning rate: 0.1151 \\
\hline Momentum factor: 0.2382 \\
\hline
\end{tabular}

Table 5: Optimized MSE.

\begin{tabular}{|l|c|}
\hline Epoch count & MSE \\
\hline 1 & $1.63289262934093 \mathrm{E}-01$ \\
\hline 100 & $1.67082747834919 \mathrm{E}-03$ \\
\hline 1000 & $1.67029292416874 \mathrm{E}-03$ \\
\hline 10000 & $1.65516581866368 \mathrm{E}-03$ \\
\hline 7000000 & $1.33629916609829 \mathrm{E}-03$ \\
\hline
\end{tabular}


The architecture of deterministic forecast is shown in Table 3.The initial trainable weights including biases of the network initialized by the random values between 0 and 1 are shown in Table 6. Error (MSE) minimizing process called epochs during the training period. After 7000000 epochs the MSE minimized up to 1.33629916609829E-03. During the training process, it has been observed that the MSE optimized regularly after each epoch. The epoch is a parallel process which minimizes the MSE as depicted in Table 5. The training started with initial set of weights between 0 and $1 \mathrm{MSE}=1.63289262934093 \mathrm{E}-01$, at beginning stage epochs MSE minimized to its lowest point. Continue the minimizing process and finally after 7000000 epochs the MSE minimized to its lowest point $1.33629916609829 \mathrm{E}-03$.

Optimum Variables of BPN: Optimized weights and biases for Desired Epochs $=7000000$ and MSE $=0.0013592475951864345$

Table 6: Optimum values of BPN variables.

\begin{tabular}{|c|c|c|c|c|c|}
\hline \multicolumn{2}{|c|}{$\begin{array}{l}\text { A. Weights in hidden layer } \\
V[i][j], \text { s.t., } i=1 . .10 \& \mathrm{j}=1 . .2\end{array}$} & \multicolumn{2}{|c|}{$\begin{array}{l}\text { B. Updated weights } \\
\text { V0[i], s.t., } \mathrm{i}=2\end{array}$} & \multicolumn{2}{|c|}{$\begin{array}{l}\text { C. Updated weights } \\
\text { W[i], s.t., } \mathrm{i}=2\end{array}$} \\
\hline $\begin{array}{l}\mathbf{V}(\mathbf{i}, \mathbf{1}) \\
0.887308 \\
0.928574 \\
0.147197 \\
0.829497 \\
0.211762 \\
0.41081 \\
0.441937 \\
0.878659 \\
0.171959 \\
0.43251 \\
\end{array}$ & $\begin{array}{c}\mathbf{V ( i , 2 )} \\
0.251494 \\
0.092413 \\
0.077776 \\
0.572786 \\
0.649765 \\
0.627184 \\
0.931653 \\
0.435436 \\
0.729914 \\
0.172895 \\
\end{array}$ & $\begin{array}{l}\mathbf{V o}(\mathbf{1}) \\
0.390054\end{array}$ & $\begin{array}{c}\mathbf{V o}(2) \\
0.694807\end{array}$ & $\begin{array}{l}\mathbf{W}(\mathbf{1}) \\
0.546431\end{array}$ & $\begin{array}{r}\mathbf{W}(\mathbf{2}) \\
0.356959\end{array}$ \\
\hline Bias in outpu & er: $1.95 \mathrm{E}-05$ & LPA $=95$ & & & \\
\hline
\end{tabular}

The performance of the model in training period as well as for the testing period is shown in figure $1 \& 2$. The actual and predicted values are well correlated.

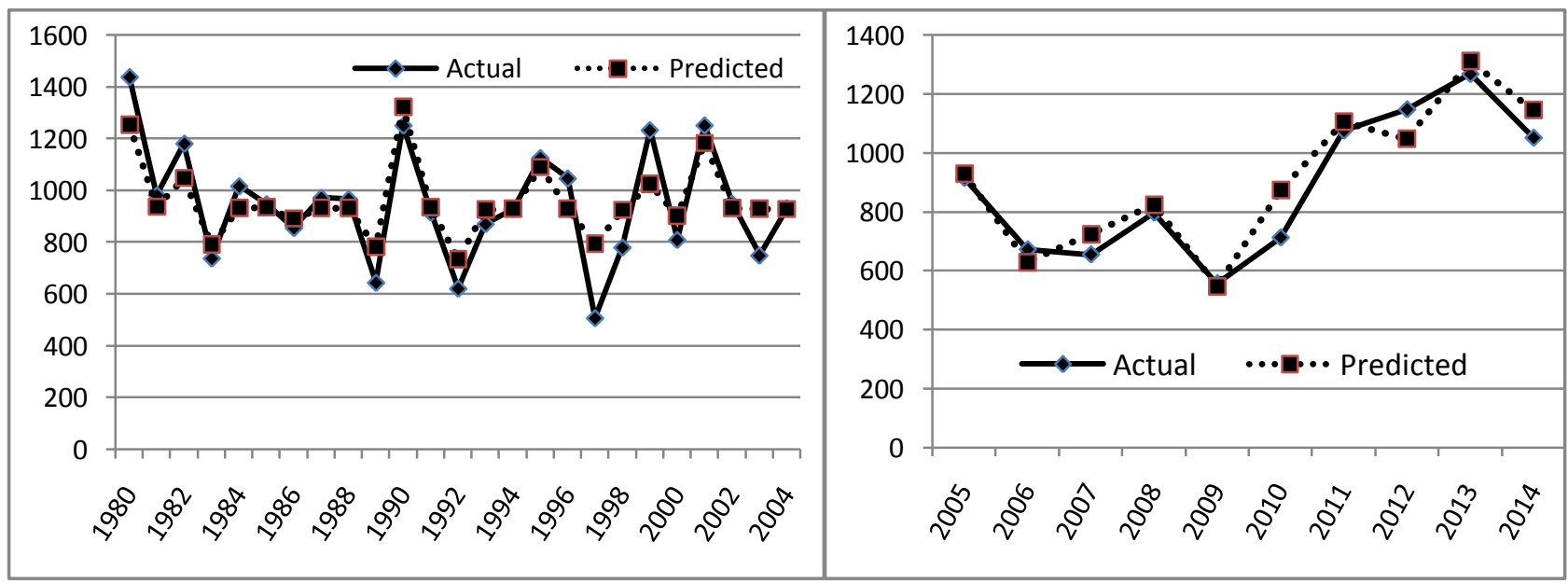

Fig.1: Performance in Training Period.

Fig.2: Performance in Testing Period. 


\section{Result and Discussion:-}

The performance of the model in training period as well as for the testing period is shown in figure $1 \& 2$. The actual and predicted values are well correlated. This study produces results with high accuracy. In order to check the performance of BPN during the testing period with new data, it was tested with the 10 years (2005-2014) of the test data. The performance of BPN model during the testing period (2005-2014) and training period (1970-2004) is illustrated in Table-1. This detail reflects the efficiency of the BPN model in prediction. The statistics of the performance of the BPN in training as well as in testing period is illustrated in table-2.

Table 7: Output of BPN Model.

\begin{tabular}{|l|l|}
\hline Statistical data of Training Period & \\
\hline Mean : & 948.19 \\
\hline Mean Absolute Deviation(MAD) : & 58.3376000000 \\
\hline SD(\% of LPA) : & 14.3726402307 \\
\hline MAD(\% of LPA) : & 6.0975395614 \\
\hline Statistical data of Testing Period & 885.48 \\
\hline Mean : & 34.6760000000 \\
\hline Mean Absolute Deviation(MAD) : & 7.2942647798 \\
\hline SD(\% of LPA) : & 3.6243911617 \\
\hline MAD(\% of LPA) : & \\
\hline Model Acceptance Decision: & $\begin{array}{l}\text { MAD(\% of mean })=6.09753956142734 \text { is less and less than half of the } \\
\text { SD(\% of mean) }=14.3726402306542\end{array}$ \\
\hline Result:- Model Accepted. &
\end{tabular}

The obtained results are illustrated in Table-7. Long period average (LPA) observed as 956.74 for 45 years data time series of vindhya region. It is observed that the MAD (6.09) is less than the SD (14.37) during the testing period. Correlation coefficient of training period is 0.89 and for testing period is 0.95 . The result reflects the efficiency of the model.

\section{Acknowledgement:-}

The authors thank to MPCST, Bhopal for the financial support. The climate data are received from IMD Pune and also thanks to Department of Computer Science, BIT Durg for academic support.

\section{References:-}

1. Karmakar, S., Kowar, M. K. and Guhathakurta, P.(2009):Artificial neural network skeleton in deterministic forecast to recognize pattern of TMRF a District, CSVTU Res. J.,2(2), 41-45.

2. Karmakar, S., Kowar, M. K. and Guhathakurta, P.(2012): Application of neural network in long range weather forecasting: In the context of smaller geographical region (i.e. Chhattisgarh State, India). Lambert Academic Publishing, Germany, 57-87.

3. Krishnamurthy, Vand Kinter III, J. L(2002): The Indian monsoon and its relation to global climate variability, in Global climate - Current researchuncertainties in the climate system, edited by Rodo, X. and Comin, F. A., Springer Berlin Heidelberg, 186-236.

4. Shrivastava G. and Karmakar S. (2013) BPN model for long-range forecast of monsoon rainfall over a very small geographical region and its verification for 2012, Geofizika UDC 551.509.331 Volume 30.

5. Sahai, A. K., Grimm, A. M., Satyan. V. and Pant, G. B.(2002): Prospects of prediction of Indian summer monsoon rainfall using global SST anomalies, IITM Research Report No. RR-093, ISSN: 0252-1075.

6. Sawaitul, S. D., Wagh, K. P. and Chatur, P. N. (2012): Classification and prediction of future weather by using back propagation algorithm-An approach, Int. J. Emerg. Tech. Adv. Eng., 2,110-113. 